\title{
Peripheral nerve injuries
}

\author{
Katerina Anesti ${ }^{1}$, Paul Caine ${ }^{2}$ \\ ${ }^{1}$ Department of Plastic Surgery, Royal Devon and Exeter NHS Foundation Trust, Exeter, EX2 5DW, UK. \\ ${ }^{2}$ Department of Plastic Surgery, St Andrew's Centre, Mid Essex NHS Trust, Chelmsford, CM1 7ET, UK.
}

Address for correspondence: Miss. Katerina Anesti, Department of Plastic Surgery, Royal Devon and Exeter NHS Foundation Trust, Exeter, EX2 5DW, UK. E-mail: katanest@doctors.org.uk

Nerve injuries caused by medical interventions (iatrogenic lesions) can complicate procedures and affect any part of the peripheral nervous system. Available data are fragmentary and little information is accessible on the overall incidence of iatrogenic nerve lesions that ranges from $1.5 \%$ to $15 \% .^{[1,2]}$ Major drawbacks are the limited number of patients studied and the incomplete and subjective assessment of nerve function. The potential for iatrogenic injuries in the course of any surgical procedure should be thoroughly appreciated by all surgeons and they should be familiar with early diagnostic steps for detecting these lesions. The importance of prompt diagnosis and adequate treatment of iatrogenic nerve injuries for optimal functional recovery should be stressed. Excellent results can be obtained if certain diagnostic and surgical principles are followed.

Iatrogenic injuries during surgery are becoming more widely documented as we begin to see surges in insurance claims. A review of insurance claims filed by patients who had undergone otorhinolaryngological procedures in Finland found a total of 422 claims over a 4-year-period. Iatrogenic nerve injury accounted for 30 patients; 10 patients suffered facial nerve damage (secondary to ear and parotid gland surgery) and 10 suffered trigeminal nerve injury (secondary to maxilary sinus surgery). ${ }^{[1]}$ A series by Kretschmer et al. ${ }^{[2]}$ looking at 722 patients with peripheral nerve trauma found that approximately $17.4 \%$ were iatrogenic injuries with the majority $(94 \%)$ being secondary to a surgical procedure. Seventeen percent of injuries occurred to the median nerve, $16 \%$ to the accessory, $13 \%$ to the radial and common peroneal, $8.5 \%$ to the ulnar and $5 \%$ to the femoral nerves, respectively. ${ }^{[3]}$ Spinal accessory nerve injuries resulting from medical intervention have been quoted as high as $94 \%{ }^{[4]}$ and figures of $60 \%$ and $25.2 \%$ for femoral

\begin{tabular}{|l|l|}
\hline \multicolumn{2}{|c|}{ Access this article online } \\
\hline Quick Response Code: & Website: \\
& www.parjournal.net \\
\hline & \\
\hline
\end{tabular}

and sciatic nerve injuries, respectively. ${ }^{[5,6]}$ Topuz et al. ${ }^{[7]}$ attributed sciatic nerve damage to intragluteal injections in approximately $40 \%$ of their patients. The high risk procedures that often result in peripheral nerve damage include: osteosynthesis, arthrodesis, posterior triangle lymph node biopsies, carpal tunnel release, surgery for varicose veins, baker cyst excision and inguinal herniorrhaphy. ${ }^{[8]}$

The use of pneumatic surgical tourniquets is a key in providing a bloodless environment in distal extremities. They also have a crucial role in the application of regional anesthesia. However, they can result in complications including: skin damage, nerve and vascular injury and also postoperative swelling. Nerve injury related to tourniquets results from two pathological processes: mechanical compression and neural ischemia. Horlocker et al..$^{[9]}$ found there to be a three-fold increase in risk of nerve damage for every $30 \mathrm{~min}$ increase in tourniquet inflation time. Tourniquet related nerve injury is widely documented in the literature, ${ }^{[10]}$ however, permanent femoral nerve injury secondary to tourniquet use is sparsely reported. Mingo-Robinet reported a permanent femoral nerve palsy secondary to tourniquet use in patella fracture surgery. ${ }^{[1]}$

It has been documented in the literature that iatrogenic nerve injury can arise from enucleation of peripheral schwannomas by both an extra and intracapsular approach. The reported incidence of iatrogenic injury has been found to range from $13 \%$ of cases for motor deficit ${ }^{12]}$ up to $50 \%$ for sensory deficit. ${ }^{[13]}$ Park et al. ${ }^{[14]}$ reported values as high as $73 \%$ of new neurological deficit after enucleation. A review of nerves injured and the length of neurological deficit was carried out by Date et al. ${ }^{[15]}$ Upper limb nerves were affected and included: the radial

This is an open access article distributed under the terms of the Creative Commons Attribution-NonCommercial-ShareAlike 3.0 License, which allows others to remix, tweak, and build upon the work non-commercially, as long as the author is credited and the new creations are licensed under the identical terms.

For reprints contact: reprints@medknow.com

How to cite this article: Anesti K, Caine P. Peripheral nerve injuries. Plast Aesthet Res 2015;2:309-10.

Received: 03-05-2015; Accepted: 06-09-2015 
nerve in 2 patients, median nerve in 3, ulnar nerve in 5 and musculocutaneous in 1 . Lower limb nerves were also affected: tibial in 13 patients, peroneal in 8, and the femoral, obturator and sciatic nerve in 3 individual patients. The degree of neurological deficit was graded according to persistence of symptoms. The review found that 22 patients developed sensory changes resolving within 6 months (Medical Research Council [MRC] motor grading system Grade 1$)^{[16]}$ and 10 patients where the deficit took in excess of 6 months to recover (MRC Grade 2). After a total of 48 months follow-up there were 4 patients in which the motor deficit or paresthesia had not recovered (MRC Grade 3). The nerves affected in these 4 patients included the median, ulnar and tibial. Of the 11 patients with schwannomas arising from the upper extremity nerve three had not recovered function by the end of follow-up. Five patients with ulnar nerve damage showed Grade 3 motor palsy with reduced abduction of the little finger. Of the 24 patients with lower limb schwannomas only 3 developed a Grade 3 motor deficit. Knight et al..$^{[17]}$ found 28 patients to have neurological deficit and/or pain after excision of schwannomas. Factors to try to reduce the neurological deficit include; avoiding unnecessary biopsy, air tourniquet use for good vision under microscope, intracapsular approach, limited incision of the epineurium, atraumatic dissection, no en bloc resection if traumatic, adequate drainage to prevent hematoma formation and to raise the affected limb. Simon et al. ${ }^{[18]}$ in a case series of 2 patients reported the benefit of using high resolution ultrasonography prior to nerve sheath tumor resection to identify normal nerve tissue.

In summary, iatrogenic nerve lesions require early clinical and electrophysiological testing and prompt referral to specialized centers for timely treatment. In cases of nerve discontinuity and acute nerve compression, surgical intervention is indicated immediately. In all other cases, 6-12 weeks after the iatrogenic lesion, primary surgery should be considered if no significant spontaneous recovery is observed. Neurapraxia carries a good prognosis, but if diagnosis is in doubt, delay may cause continuing compression or ischemia, which will result in worsening of the nerve lesion to axonotmesis or even neurotmesis. Furthermore, when dealing with traumatic neuropathies, adequate pain management is likely to have a strong positive influence in the prognosis of these patients, both in terms of improving their quality of life and functional recovery. The role of aggressive physiotherapy with motor and sensory re-education will facilitate rehabilitation and useful functional restoration. It seems imperative to know more about long-term function and quality of life, since these injuries may lead to severe psychological distress.

In conclusion, iatrogenic nerve injuries constitute a complex, multifactorial problem, which cannot be resolved by surgery alone. The management should embrace prevention, early diagnosis and appropriate treatment with rehabilitation, psychological support and control of pain. This warrants the highest quality of care in nerve reconstruction.
Complications should be referred and dealt with promptly by experienced surgeons with adequate microsurgical training, to ensure best chances for successful outcome. In addition, when nerve damage is caused by medical intervention, legal issues may ensue. The importance of preoperative counseling about the potential injury and precise documentation of intraoperative and postoperative findings cannot be overemphasized. This will facilitate postoperative discussion of any surgical complication.

\section{Financial support and sponsorship} Nil.

\section{Conflicts of interest}

There are no conflicts of interest.

\section{REFERENCES}

I. Lehtivouri T, Palonen R, Mussalo-Rauhamaa H, Holi T, Henriksson M, Aaltonen LM. Otorhinolaryngological patient injures in finland. Laryngoscope 2013;123:2397-400.

2. Kretschmer T, Antoniadis G, Braun V, Rath SA, Richter HP. Evaluation of iatrogenic lesions in 722 surgically treated cases of peripheral nerve trauma. J Neurosurg 2001;94:905-12.

3. Antoniadis G, Kretschmer T, Pedro MT, König RW, Heinen CP, Richter HP. latrogenic nerve injuries: prevalence, diagnosis and treatment. Dtsch Arztebl Int 20|4; I | I:273-9.

4. Kim DH, Cho YJ, Tiel RL, Kline DG. Surgical outcomes of I I I spinal accessory nerve injuries. Neurosurgery 2003;53:I 106-I2.

5. Kim DH, Murovic JA, Tiel R, Kline DG. Management and outcomes in 353 surgically treated sciatic nerve lesions. J Neurosurg 2004;101:8-17.

6. Kim DH, Murovic JA, Tiel RL, Kline D. Intrapelvic and thigh-level femoral nerve lesions: management and outcomes in 119 surgically treated cases. J Neurosurg 2004;100:989-96.

7. Topuz K, Kutlay M, Simsek H, Atabey C, Demircan M, Senol Güney M. Early surgical treatment protocol for sciatic nerve injury due to injection-a retrospective study. Br J Neurosurg 201 I;5:509-15.

8. Stöhr M. latrogenic nerve lesions. Injection, operation, storage, radiotherapy. 2nd ed. Stuttgart: Thieme; 1996. p. I3I-9I.

9. Horlocker TT, Hebl JR, Gali B, Jankowski CJ, Burkle CM, Berry DJ, Zepeda FA, Stevens SR, Schroeder DR. Anesthetic, patient, and surgical risk factors for neurologic complications after prolonged total tourniquet time during total knee arthroplasty. Anesth Analg 2006; 102:950-5.

10. Kornbluth ID, Freedman MK, Sher L, Frederick RW. Femoral, saphenous nerve palsy after tourniquet use: a case report. Arch Phys Med Rehabil 2003;84:909-II.

II. Mingo-Robinet J, Castañeda-Cabrero C, Alvarez V, León Alonso-Cortés JM, Monge-Casares E. Tourniquet-related iatrogenic femoral nerve palsy after knee surgery: case report and review of the literature. Case Rep Orthop 20|3;20|3:368290.

12. Donner TR, Voorhies RM, Kline DG. Neural sheath tumors of major nerves. J Neurosurg 1994;81:362-73.

13. Oberle J, Kahamba J, Richter HP. Peripheral nerve schwannomas - An analysis of 16 patients. Acta Neurochir (Wien) 1997;139:949-53.

14. Park MJ, Seo KN, Kang HJ. Neurological deficit after surgical enucleation of schwannomas of the upper limb. J Bone Joint Surg Br 2009;9I:1482-6.

15. Date R, Muramatsu K, Ihara K, Taguchi T. Advantages of intra-capsular micro-enucleation of schwannoma arising from extremities. Acta Neurochir (Wien) 2012; I54: I73-8.

16. Medical Research Council Scale. Aids to examination of the peripheral nervous system. Memorandum no. 45. London: Her Majesty's Stationery Office; 1976.

17. Knight DM, Birch R, Pringle J. Benign solitary schwannomas: a review of 234 cases. J Bone Joint Surg Br 2007;89:382-7

18. Simon NG, Cage T, Narvid J, Noss R, Chin C, Kliot M. High-resolution ultrasonography and diffusion tensor tractography map normal nerve fascicles in relation to schwannoma tissue prior to resection. J Neurosurg 2014;120:1 II3-7. 